\title{
Incidence of cancer among commercial airline pilots
}

\author{
Vilhjálmur Rafnsson, Jón Hrafnkelsson, Hrafn Tulinius
}

\begin{abstract}
Objectives-To describe the cancer pattern in a cohort of commercial pilots by follow up through the Icelandic Cancer Registry.

Methods-This is a retrospective cohort study of 458 pilots with emphasis on subcohort working for an airline operating on international routes. A computerised file of the cohort was record linked to the Cancer Registry by making use of personal identification numbers. Expected numbers of cancer cases were calculated on the basis of number of person-years and incidences of cancer at specific sites for men provided by the Cancer Registry. Numbers of separate analyses were made according to different exposure variables. Results-The standardised incidence ratio (SIR) for all cancers was $0.97(95 \%$ confidence interval (95\% CI) 0.62 to 1.46 ) in the total cohort and $1.16(95 \%$ CI 0.70 to 1.81) among those operating on international routes. The SIR for malignant melanoma of the skin was $10.20,95 \%$ CI 3.29 to 23.81 in the total cohort and 15.63 , $95 \%$ CI 5.04 to 36.46 in the restricted cohort. Analyses according to number of block-hours and radiation dose showed that malignant melanomas were found in the subgroups with highest exposure estimates, the SIRs were 13.04 and 28.57 respectively. The SIR was 25.00 for malignant melanoma among those who had been flying over five time zones.

Conclusions-The study shows a high occurrence of malignant melanoma among pilots. It is open to discussion what role exposure of cosmic radiation, numbers of block-hours flown, or lifestyle factors-such as possible excessive sunbathing-play in the aetiology of cancer among pilots. This calls for further and more powerful studies. The excess of malignant melanoma among those flying over five time zones suggests that the importance of disturbance of the circadian rhythm should be taken into consideration in future studies.

(Occup Environ Med 2000;57:175-179)
\end{abstract}

Keywords: cancer registry; malignant melanoma of the skin; cosmic radiation; block-hours; time zones

Recent retrospective cohort studies on commercial pilots have results which are inconsistent for risk of cancer. ${ }^{1-4}$ The first Canadian study showed increased mortalities for rectal and brain cancers and increased incidences of non-melanoma skin cancer, cancer of the brain, and Hodgkin's disease, and nonsignificant excess for malignant melanoma, and cancer of the rectum and prostate. ${ }^{1}$ In the second Canadian study the incidence of prostate cancer and acute myeloid leukaemia was increased and there was a non-significant excess for malignant melanoma, brain tumours, and non-chronic lymphoid leukaemia. ${ }^{2}$ In a study from Japan the mortality for all cancers was averaged, and apparently because of the small numbers in the study the rates were not calculated for different cancers. ${ }^{3}$ A recent study of British Airways pilots showed a standardised mortality ratio (SMR) of 333 for malignant melanoma, and non-significant excess of cancer of the brain, central nervous system, and colon. ${ }^{4}$

Other studies have indicated increased risk of cancer of the colon, brain, Hodgkin's disease, and malignant melanoma in pilots..$^{5-7}$ Studies on air force and navy pilots have also indicated increased risk of some cancer sites notably testis, urinary bladder, Hodgkin's disease, and malignant melanoma. ${ }^{8}{ }^{9}$ However, these studies are in many ways not comparable with the studies on commercial airline pilots. Further evaluations on the relation between cancer of the brain and nervous system and exposure to radiation have been done in nested case-control studies in the United States air force..$^{11}$

Occupational or occupationally related exposures of commercial airline pilots have been mentioned previously. ${ }^{12}$ The discussion has mainly focused on ionising radiation, engine exhaust gases, ozone, electromagnetic fields, and radiofrequency radiation; and lifestyle factors - such as irregular working hours, disturbance of the circadian rhythm, and easy access to tax free tobacco and alcohol. Cosmic radiation has been considered to be the most important risk factor. ${ }^{13-16}$ Cosmic radiation differs from the exposure in the nuclear industry because of a larger proportion of neutrons. Cancer risk among pilots has recently attracted attention and the possible causes have often been discussed. The well known risk of colorectal cancer among workers with sedentary occupations ${ }^{17}$ has been mentioned in former studies. ${ }^{25}$ The excess risk of malignant melanoma has also been explained by excessive sunbathing, ${ }^{67}$ but no study has yet documented the sun exposure habits of pilots, although the opportunity for intense sun bathing has been predicted for British and Swedish pilots. $^{7}$

Studies on pilots have thus not yet shown consistent cancer patterns. This study was 
intended to contribute to the picture by following a cohort of commercial airline pilots in the Icelandic Cancer Registry.

\section{Methods}

The cohort comprised 458 men. These were all licensed commercial pilots in Iceland according to computerised files from the Icelandic Aviation Authority. These files and the other registers mentioned later were used to compile a computer file of pilots. Permission was obtained from the Data Protection Commission to produce this file and to link the records with other registers. Each pilot's personal identification number, which includes his date of birth, was obtained from the National Registry using the name, date of birth, and home address. A computerised member list from the Icelandic Pilots Association and the published Book of pilots (Flugmannatal) ${ }^{18}$ were complementary to the information from the aviation authority. The Book of pilots included information on the pilots' professional careers. The subjects entered the study the year they became licensed.

Altogether 265 pilots out of the total cohort had been employed by Icelandair, formerly Flugfélag Íslands (Icelandair, established 1937) and Loftleidir (Icelandic Airlines, established 1944). Since 1945 Icelandair has had regular European routes and from 1952 regular routes to North America and low priced transatlantic routes. As the company records contained extensive information about the pilot's career the study is mainly restricted to those ever employed at Icelandair. The company records included information on name, date of birth, and personal identification number, as well as information on time of employment, type of aeroplanes, and periods when in use. For all pilots employed in the year 1985 and thereafter the company files included information on the type of aeroplane, and number of block-hours flown each year by each pilot. Block-hours is a measurement of the time interval from the time the aircraft starts to move under its own power until it comes to a stop at the destination airport.

The personal identification number of each subject was used in record linkage to the National Registry to confirm date of death or date of emigration. In that way it was possible to ascertain the vital status of the total cohort. A second record linkage was made to the Icelandic Cancer Registry, which is a nation wide registry of cancer cases, more than $94 \%$ of which have been histologically verified. ${ }^{19}$

Person-years were calculated for each pilot, starting on the first year in the study or 1955, the first year of the Cancer Registry, whichever came later and ending with his date of death or emigration or at the end of 1997, the last year in the follow up period, whichever came first. ${ }^{20}$ The number of expected cancers was calculated on the basis of person-years for each 5 year age category and the incidences of cancer for the male population in Iceland obtained from the Icelandic Cancer Registry. The ratio between observed and expected numbers of cancer or the standardised incidence ratio
Table 1 Division of the subcohort ever employed at Icelandair according to accumulated block hours flown, estimated accumulated radiation dose, and whether ever flying over five time zones

\begin{tabular}{lrr}
\hline & $n$ & mean \\
\hline Accumulated block hours: & 77 & 2213 \\
-4.999 & 75 & 7169 \\
$5.000-9.999$ & 113 & 17694 \\
$\geqslant 10.000$ & 87 & \\
Accumulated radiation dose (mSv): & & 1.3 \\
-2.9 & 49 & 6.7 \\
$3-9.9$ & 62 & 14.8 \\
$10-19.9$ & 67 & 30.9 \\
$\geqslant 20$ & 148 & \\
Flying over five time zones & 117 & \\
Ever & & \\
Never & & \\
\hline
\end{tabular}

(SIR) was calculated with the $95 \%$ confidence interval (95\% CI) assuming a Poisson distribution and making use of Byar's approximation. ${ }^{20}$

Detailed information was available for those pilots who had been employed by Icelandair. Through information from the company and the pilots' association it was possible to estimate number of block-hours per aircraft type for the 265 pilots ever employed by Icelandair including the 57 who had ended their employment before 1985. Separate analysis was performed dividing the cohort into three subgroups according to accumulated block-hours: those with $\leqslant 4999$ hours, 5000-9999 hours, and $\geqslant 10000$ hours as shown in table 1 .

The cohort was also analysed according to estimated dose of cumulative cosmic radiation. The types of aircraft were classified into three categories and assigned the appropriate amount of $\mu \mathrm{Sv} / \mathrm{block}$-hour according to measurements made on SAS pilots. ${ }^{15}$ The first category included all propeller driven aircraft allocated a radiation dose of $0.2 \mu \mathrm{Sv} / \mathrm{block}-$ hour, the second category included Boeing 727 and 737 allocated $2 \mu \mathrm{Sv} /$ block-hour, and the third category included Douglas DC 8 and DC 10, and Boeing 757 allocated $3 \mu$ Sv/blockhour. The accumulated $\mathrm{mSv}$ for each pilot was calculated by multiplying the amount of $\mu \mathrm{Sv} /$ block-hour by number of block-hours for each aircraft type and adding the products. The cohort was divided into four subgroups according to the following cumulative radiation dose: $\leqslant 2.9 \mathrm{mSv}, 3-9.9 \mathrm{mSv}, 10-19.9 \mathrm{mSv}$, and $\geqslant 20$ $\mathrm{mSv}$ as shown in table 1 .

In an attempt to evaluate the possible relation between disturbance of circadian rhythm, jet lag, and risk of cancer the cohort was divided into two groups: those who had ever flown between Iceland and North America and those who had only flown within Europe disregarding the flight time or the periods flown. There is a 5 hour time difference between Iceland (Greenwich mean time), and the east coast of North America, (eastern time). Trips to Europe were usually made by the same aircrew back and forth on the same day, whereas a trip to North America was followed by a stop over for some days.

To eliminate the effect of selection of pilots into different exposure groups in the separate analyses, we allowed 5 years to elapse before the counting of person-years began, as was recommended by McDonald et al. ${ }^{21}$ 
Table 2 Observed (Obs) and expected (Exp) number of cancers, SIR (95\% CI) among 458 pilots (9215.5 person-years, 1955-97)

\begin{tabular}{|c|c|c|c|c|}
\hline Cancer sites $(I C D-7) *$ & Obs & $\operatorname{Exp}$ & $\operatorname{SIR}$ & $95 \% C I$ \\
\hline All cancers $(140-205)$ & 23 & 23.68 & 0.97 & 0.62 to 1.46 \\
\hline Oesophagus (150) & 1 & 0.36 & 2.78 & 0.04 to 15.45 \\
\hline Colon (153) & 1 & 1.57 & 0.64 & 0.01 to 3.54 \\
\hline Gall bladder (155.1) & 1 & 0.12 & 8.33 & 0.11 to 46.36 \\
\hline Lung (162) & 2 & 3.13 & 0.64 & 0.07 to 2.31 \\
\hline Prostate (177) & 5 & 3.91 & 1.28 & 0.41 to 2.98 \\
\hline Kidney (180) & 2 & 1.41 & 1.42 & 0.16 to 5.12 \\
\hline Malignant melanoma of the skin (190) & 5 & 0.49 & 10.20 & 3.29 to 23.81 \\
\hline Eye (192) & 1 & 0.10 & 10.00 & 0.13 to 55.64 \\
\hline Brain (193) & 2 & 1.14 & 1.75 & 0.20 to 6.33 \\
\hline Thyroid (194) & 1 & 0.67 & 1.49 & 0.02 to8.30 \\
\hline Unspecified sites (199) & 1 & 0.49 & 2.04 & 0.03 to 11.35 \\
\hline Leukaemia (204) & 1 & 0.59 & 1.69 & 0.02 to 9.43 \\
\hline Acute myeloid leukaemia (204) & 1 & 0.26 & 3.85 & 0.05 to 21.40 \\
\hline
\end{tabular}

* Categories with only one cancer case are shown for the sake of completeness.

ICD-7 = International classification of diseases, 7 th revision.

Table 3 Observed (Obs) and expected (Exp) number of cancers, SIR (95\% CI) among 265 pilots (5696.0 person-years 1955-97) ever employed at Icelandair

\begin{tabular}{|c|c|c|c|c|}
\hline Cancer sites (ICD-7) & Obs & $\operatorname{Exp}$ & $S I R$ & $95 \% C I$ \\
\hline All cancers (140-205) & 19 & 16.43 & 1.16 & 0.70 to 1.81 \\
\hline Oesophagus (150) & 0 & 0.26 & 0.00 & - to 14.11 \\
\hline Colon (153) & 0 & 1.10 & 0.00 & - to 3.33 \\
\hline Gall bladder (155.1) & 1 & 0.08 & 12.50 & 0.16 to69.55 \\
\hline Lung (162) & 2 & 2.24 & 0.89 & 0.10 to 3.22 \\
\hline Prostate (177) & 4 & 2.84 & 1.41 & 0.38 to 3.61 \\
\hline Kidney $(180)$ & 2 & 0.99 & 2.02 & 0.23 to 7.29 \\
\hline Malignant melanoma of the skin (190) & 5 & 0.32 & 15.63 & 5.04 to 36.46 \\
\hline Eye $(192)$ & 1 & 0.07 & 14.29 & 0.19 to 79.48 \\
\hline Brain (193) & 2 & 0.76 & 2.63 & 0.30 to 9.50 \\
\hline Thyroid (194) & 1 & 0.44 & 2.27 & 0.03 to 12.64 \\
\hline Unspecified sites (199) & 0 & 0.33 & 0.00 & - $\quad$ to 11.12 \\
\hline Leukaemia (204) & 1 & 0.40 & 2.50 & 0.03 to 13.91 \\
\hline Acute myeloid leukaemia (204) & 1 & 0.17 & 5.88 & 0.08 to 32.73 \\
\hline
\end{tabular}

Footnotes as for table 2 .

Table 4 Observed (Obs) and expected (Exp) number of all cancers and malignant melanoma of the skin, SIR (95\% CI) among pilots employed at Icelandair according to three categories of accumulated block hours with a requirement of a 5 year time interval before the start of follow up

\begin{tabular}{|c|c|c|c|c|}
\hline Cancer sites (ICD-7) & Obs & $\operatorname{Exp}$ & $S I R$ & $95 \% C I$ \\
\hline \multicolumn{5}{|l|}{ Accumulated block-hours 0-4999: } \\
\hline All cancers $(140-205)$ & 2 & 1.93 & 1.04 & 0.12 to3.74 \\
\hline Malignant melanoma of the skin (190) & 0 & 0.02 & 0.00 & - to 183.40 \\
\hline \multicolumn{5}{|l|}{ Accumulated block-hours 5000-9999: } \\
\hline All cancers $(140-205)$ & 6 & 1.97 & 3.05 & 1.11 to 6.63 \\
\hline Malignant melanoma of the skin (190) & 2 & 0.05 & 40.00 & 4.49to 144.42 \\
\hline \multicolumn{5}{|l|}{ Accumulated block-hours $\geqslant 10000$ : } \\
\hline All cancers $(140-205)$ & 9 & 12.13 & 0.74 & 0.34 to 1.41 \\
\hline Malignant melanoma of the skin (190) & 3 & 0.23 & 13.04 & 2.62 to 38.11 \\
\hline
\end{tabular}

Footnotes as for table 2 .

Table 5 Observed (Obs) and expected (Exp) number of all cancers and malignant melanoma of the skin SIR (95\% CI) among pilots employed at Icelandair according to estimaated dose of additional accumulated cosmic radiation from flying with a requirement of a 5 year time interval before the start of follow up

\begin{tabular}{|c|c|c|c|c|}
\hline Cancer sites (ICD-7) & Obs & $\operatorname{Exp}$ & $S I R$ & $95 \% C I$ \\
\hline \multicolumn{5}{|l|}{ Accumulated cosmic radiation $0-2.9 \mathrm{mSv}$ : } \\
\hline All cancers $(140-205)$ & 4 & 4.47 & 0.89 & 0.24 to 2.29 \\
\hline Malignant melanoma of the skin (190) & 0 & 0.05 & 0.00 & - $\quad$ to73.36 \\
\hline \multicolumn{5}{|l|}{ Accumulated cosmic radiation $3-9.9 \mathrm{mSv}$ : } \\
\hline All cancers $(140-205)$ & 7 & 1.19 & 5.88 & 2.36 to 12.12 \\
\hline Malignant melanoma of the skin (190) & 2 & 0.03 & 66.67 & 7.49 to 240.70 \\
\hline \multicolumn{5}{|l|}{ Accumulated cosmic radiation $10-19.9 \mathrm{mSv}$ : } \\
\hline All cancers $(140-205)$ & 4 & 2.08 & 1.92 & 0.52 to 4.92 \\
\hline Malignant melanoma of the skin (190) & 1 & 0.03 & 33.33 & 0.44 to 185.46 \\
\hline \multicolumn{5}{|l|}{ Accumulated cosmic radiation $\geqslant 20 \mathrm{mSv}$ : } \\
\hline All cancers $(140-205)$ & 4 & 3.72 & 1.08 & 0.29 to 2.75 \\
\hline Malignant melanoma of the skin (190) & 2 & 0.07 & 28.57 & 3.21 to 103.16 \\
\hline
\end{tabular}

Footnotes as for table 2 . not include unity). There was also an excess of prostate cancer, kidney cancer, and brain cancer; however, the 95\% CIs were wide and included unity. For many sites the observed cancers were few. The categories with only one cancer case are shown for the sake of completeness and to explain why cancer sites were subsequently selected.

As malignant melanoma of the skin was so prominent in the results we looked for the histological type of the other cancer sites in the Cancer Registry and found that histologically ocular cancer was also malignant melanoma.

One of the malignant melanomas of the skin was on the head and neck, two were on the trunk and two were located on the limbs. The histology of the melanomas were of two types, four were superficial spreading and one was the lentigenous type.

Table 3 shows the results when a restriction was made to those ever employed by Icelandair. Altogether there were 19 cancers versus 16.43 expected. There was an excess for the same cancer sites as in the total cohort. The SIR for malignant melanoma was 15.63.

Table 4 shows the SIR for all cancers and malignant melanoma according to accumulated numbers of block-hours. Among those who had 5000-9999 block-hours the SIR for all cancers was 3.05 and for malignant melanoma the SIR was 40 . The SIR for malignant melanoma was also high among those with $\geqslant 10000$ block-hours.

Table 5 shows the observed and expected numbers of all cancers and malignant melanoma among pilots ever employed by Icelandair according to estimated dose of additional accumulated radiation from flying. There was no malignant melanoma among those with the lowest radiation dose and the SIR for malignant melanoma was high among those with large doses of accumulated radiation.

Table 6 shows the observed and expected number of cases for selected cancer sites according to whether the pilots had ever flown over five time zones. Four malignant melanomas, the ocular melanoma, and the leukaemia occurred in the subgroup ever flying over five time zones.

\section{Discussion}

The excess of malignant melanoma of the skin is the most significant finding in the present study. However, this is based on few cases and the $95 \%$ CIs are broad. This is consistent with results from the study of British Airways pilots ${ }^{4}$ and the two studies by Band et $a l^{12}$ which showed excess of malignant melanoma although the excess was not significant in all analyses. Other studies have also found an excess of malignant melanoma among professional pilots $^{67}$ and in all pilots. ${ }^{3}$ The United States air force aircrews had a high incidence of malignant melanoma compared with the population, however, they only had moderately increased rate for malignant melanoma compared with non-flying officers. ${ }^{8}$ In the study on cancer registration data in England and Wales and in Sweden, armed forces and military work
The SIR for all cancers was 0.97. There excess for malignant melanoma (SIR 10.20 and the $95 \%$ confidence interval (95\% CI) did 
Table 6 Observed (Obs) and expected (Exp) number for all cancers, malignant melanoma of the skin and eye, and leukaemia SIR (95\% CI) among pilots employed at Icelandair according to whether ever flying over five time zones with a requirement of a 5 year time interval before the start of follow up

\begin{tabular}{|c|c|c|c|c|}
\hline Cancer sites (ICD-7) & Obs & $\operatorname{Exp}$ & $S I R$ & $95 \% C I$ \\
\hline \multicolumn{5}{|l|}{ Never flying over five time zones: } \\
\hline All cancers $(140-205)$ & 12 & 8.35 & 1.44 & 0.74 to 2.51 \\
\hline Malignant melanoma of the skin (190) & 1 & 0.11 & 9.09 & 0.12 to 50.58 \\
\hline Eye $(192)$ & 0 & 0.03 & 0.00 & - $\quad$ to 122.27 \\
\hline Acute myeloid leukaemia (204) & 0 & 0.08 & 0.00 & to 45.85 \\
\hline \multicolumn{5}{|l|}{ Ever flying over five time zones: } \\
\hline All cancers $(140-205)$ & 7 & 6.70 & 1.04 & 0.42 to 2.15 \\
\hline Malignant melanoma of the skin (190) & 4 & 0.16 & 25.00 & 6.73 to 64.00 \\
\hline Eye $(192)$ & 1 & 0.03 & 33.33 & 0.44 to 185.46 \\
\hline Acute myeloid leukaemia (204) & 1 & 0.07 & 14.29 & 0.19 to 79.48 \\
\hline
\end{tabular}

Footnotes as for table 2 .
Nordic countries. The subcohort at Icelandair had more radiation from employment than the male population in Iceland, but the subcohort and the reference population are considered to have sustained equal amounts of radiation from terrestrial sources. The estimated additional annual radiation dose in our study is $1-2 \mathrm{mSv}$ which is lower than has been estimated for British Airways and United States pilots. ${ }^{13} 1416$ This dose is well within the limits for occupational exposure to radiation of an adult. $^{1416}$

The incidence of malignant melanoma was highest among those who had flown routes that extended over five time zones indicating that disturbance of the circadian rhythm and thus the homeostasis of melatonin may play a part in the aetiology of melanomas. Melatonin has an oncostatic action and has been tried in the treatment of metastatic melanoma. ${ }^{34}$ The small size of our study does not allow us to separate between the theoretical synergism, or additive effect, of cosmic radiation, disturbed circadian rhythm, and the potential confounding of possible excessive sunbathing.

The excess of malignant melanoma in the present study is based on five cases, which were located on various body parts and of two histological types. It is therefore not possible to draw any conclusions from these cases according to different location or histology. ${ }^{36}$ Nevertheless, it is the second largest series of malignant melanomas yet published in retrospective cohort studies among commercial pilots. ${ }^{1-3}$ Only the British Airways study had more cases of malignant melanoma. ${ }^{4}$

In this cohort there was no case of squamous cell cancer of the skin (0.51 expected); however, there were some cases of basal cell carcinoma not reported here as they are not regularly registered in the Cancer Registry and so the information on basal cell carcinoma is thus not considered to be reliable. In the first Canadian study there was an excess of non-melanoma skin cancer when squamous cell cancer and basal cell carcinoma were grouped together. ${ }^{1}$

Of course it is not possible to say much about the one case of malignant melanoma of the eye found among the pilots. In a recent casecontrol study of ocular melanoma, an increased risk, odds ratio 3.0, was found for occupational groups who had intense exposure to ultraviolet light. ${ }^{37}$ Other risk factors for ocular melanoma are welding exposure, work as chemists, blue eyes, blonde hair, and indoor work ${ }^{37} 38$ similar to malignant melanoma of the skin. Neither is it possible to draw any conclusion from the finding of one case of acute myeloid leukaemia among the pilots although this type of cancer has been associated with exposure to radiation in other studies.

The non-significant excess of cancer of the brain and prostate, and the deficit of lung cancer in the present study agree with former studies of commercial pilots. ${ }^{1246}$ In the total cohort there was a small deficit of all cancers, and after the restriction was made to those ever employed at Icelandair there was a small excess for all cancers. This contradicts with what was done in a similar way as planned in a forthcoming study on pilots from all the 
found among Canadian, Japanese, and British Airways pilots, ${ }^{1-4}$ who showed deficits for all cancers.

The pilots who had emigrated from Iceland could not be followed up in the Cancer Registry. Altogether 66 people had emigrated during the follow up period, 15 from the restricted cohort. Most had emigrated after limited periods of employment. This happened during a time of business depression at the beginning of the 1970s. Only one pilot had emigrated after retirement. This emigration has thus diminished the detection power of the study in a similar way as those who died of aircraft accidents. Because of the comprehensive healthcare system in Iceland we are aware of an additional one case of malignant melanoma of the skin in a pilot after he had emigrated, which consequently was not included in the study.

The small size of the study is an obvious handicap leaving us with wide $95 \%$ CIs. The strength of the study is the use of the comprehensive population registers in Iceland, the National Registry, and the Icelandic Cancer Registry. The universal use of the identification numbers made it possible to ascertain vital status for all cohort members and could secure complete identification of cancer cases in the nationwide Cancer Registry. A high proportion of the cancer cases reported to the Cancer Registry were histologically verified as already mentioned. ${ }^{19}$ The use of incidence data provided an opportunity to study cancer - such as malignant melanoma - with a good survival, an advantage compared with mortality as an end point.

In conclusion the most important results of this study of pilots is the high rate of malignant melanoma in the cohort. The role of exposure to cosmic radiation, number of block-hours flown, and lifestyle factors-such as possible excessive sunbathing - in the aetiology of cancer among pilots is still open to discussion. This calls for further and more powerful studies. The excess of malignant melanoma among pilots flying over five time zones suggests that disturbance of the circadian rhythm should be taken into consideration in future studies.

We thank the staff and the management of Icelandair, the Icelandic Pilots Association, and the Icelandic Aviation Authority for allowing us access to their registers. Without their kind co-operation this study would not have been conducted.

1 Band PR, Spinelli JJ, Ng VTY, et al. Mortality and cancer incidence in a cohort of commercial airline pilots. Aviat Space Environ Med 1990;61:299-302.

2 Band PR, Le ND, Fang R, et al. Cohort study of Air Canada pilots: mortality, cancer incidence and leukemia risk. $A m \mathcal{F}$ Epidemiol 1996;143:137-43.

3 Kaji M, Tango T, Asukata I, et al. Mortality experience of cockpit crewmembers from Japan Airlines. Aviat Space Environ Med 1993;64:748-50.

4 Irvine D, Davies DM. British Airways flightdeck mortality study, 1950-92. Aviat Space Environ Med 1999;70:548-55.

5 Salisbury DA, Band PR, Threfall WJ, et al. Mortality among British Columbia pilots. Aviat Space Environ Med 1991;62: $351-2$.

6 Irvine D, Davies DM. The mortality of British Airways pilots 1966-89: a proportional mortality study. Aviat Space Environ Med 1992;63:276-9.

7 Vågerö D, Swerdlow AJ, Beral V. Occupation and malignant melanoma: a study based on cancer registration data in England and Wales and in Sweden. Br F Ind Med 1990;47: 317-24.
8 Grayson JK, Lyons TJ. Cancer incidence in United States air force aircrew, 1975-89. Aviat Space Environ Med 1996; 67:101-4.

9 Hoiberg A, Blood C. Age-specific morbidity among navy pilots. Aviat Space Environ Med 1983;54:912-18.

10 Grayson JK. Radiation exposure, socioeconomic status, and brain tumor risk in the US air force: a nested case-control study. Am $\mathcal{F}$ Epidemiol 1996;143:480-6.

11 Grayson JK, Lyons TJ. Brain cancer, flying, and socioeconomic status: a nested case-control study of USAF aircrew. Aviat Space Environ Med 1996;67:1152-4.

12 Blettner M, Grosche B, Zeeb H. Occupational cancer risk in pilots and flight attendants: current epidemiological knowledge. Radiat Environ Biophys 1998;37:75-80.

13 Friedberg W, Faulkner DN, Snyder L, et al. Galactic cosmic radiation exposure and associated health risk for air carrier crewmembers. Aviat Space Environ Med 1989;60:1104-8.

14 Bagshaw M, Irvine D, Davies DM. Exposure to cosmic radiation of British Airways flying crew on ultralonghaul routes. Occup Environ Med 1996;53:495-8.

15 Tveten U. Cosmic radiation and airline pilots. Exposure pattern of Norwegian SAS-pilots 1960-94. Kjeller: Instute for Energy Technology, 1997.

16 Nicholas JS, Lackland DT, Butler GC, et al. Cosmic radiation and magnetic field exposure to airline flight crews. $\mathrm{Am}$ F Ind Med 1998;34:547-80.

17 Potter JD, Slatter ML, Gastrup SM. Colon cancer: a review of the epidemiology. Epidemiol Rev 1993;15:499-545.

18 Steinthórsson SB, Axelsson AG, Snorrason S. Flugmannatal. (Register of Pilots). Reykjavik: Félag íslenskra atvinnuflugmanna, 1988.

19 Tulinius H, Ragnarsson J. Cancer incidence in Iceland 1955-84. Reykjavik, Cancer Society and Director General of Health, 1987.

20 Breslow NE, Day NE. Statistical methods in cancer research. Vol II. The design and analysis of cohort studies. Lyon: International Agency for Research on Cancer, 1987.

21 McDonald JC, Liddel FDK, Gibbs GW, et al. Dust exposure and mortality in chrysotile mining, 1910-75. Br f Ind Med 1980;37:11-24.

22 Gallagher RP, Elwood JM, Threlfall WJ, et al. Occupation and risk of cutaneous melanoma. Am $f$ Ind Med 1986;9:289-94.

23 Goodman KJ, Bible ML, London S, et al. Proportional melanoma incidence and occupation among white males in Los Angeles County (California, United States). Cancer Causes Control 1995;6:451-9.

24 Fritschi L, Siemiatycki J. Melanoma and occupation: results of a case-control study. Occup Environ Med 1996;53:16873.

25 Armstrong BK, English DR. Cutaneous malignant melanoma. In: Schottenfeld D, Fraumeni JF, eds. Cancer epidemiology and prevention, 2nd ed. New York: Oxford University Press, 1996.

26 Holman CDJ, Armstrong BK, Heenan PJ, et al. The causes of malignant melanoma: results from the West Australian Linos melanoma research project. Recent Results Cancer Res 1986;102:18-37.

27 Austin DF, Reynolds P. Occupation and malignant melanoma of the skin. Recent Results Cancer Res 1986;102: 98-107.

28 Schwartzbaum JA, Setzer RW, Kupper LL. Exposure to ionizing radiation and risk of cutaneous malignant melanoma Search for error and bias. Ann Epidemiol 1994;4:487-96.

29 Pion IA, Rigel DS, Garfinkel L, et al. Occupation and risk of malignant melanoma. Cancer 1995;15(suppl):637-44.

30 Acquavella JF, Wilkinson GS, Tietjen GL. A melanoma case-control study at the Los Alamos National Laboratory. Health Phys 1983;45:587-92.

31 Kendall GM, Muirhead CR, MacGibbon BH, et al. Mortality and occupational exposure to radiation: first analysis of the National Registry for Radiation Workers. BMF 1992;304:220-5

32 Thompson DE, Mabuchi K, Ron E, et al. Cancer incidence in atomic bomb survivors. Part II: solid tumors, 1958-87. Radiat Res 1994;137:S17-67.

33 Parkin DM, Muir CS, Whelan SL, et al. Cancer incidence in five continents. Vol VI. Lyon: International Agency for Research on Cancer, 1992

$34 \mathrm{Hu}$ DN, McCormick SA, Roberts JE. Effects of melatonin, its precursors and derivatives on the growth of cultured human uveal melanoma cells. Melanoma Res 1998;8:20510 .

35 Lissoni $\mathrm{P}$, Brovio $\mathrm{O}$, Brivio F, et al. Adjuvant therapy with pineal hormone melatonin in patients with lymph node relapse due to malignant melanoma. F Pineal Res 1996;21: 239-42.

36 Jonsson JG, Magnusson B, Tulinius $\mathrm{H}$, et al. Malignant melanoma in Iceland 1955-84. Leknabladid 1985;71:27481 .

37 Holly EA, Aston DA, Ahn DK, et al. Intraocular melanoma linked to occupations and chemical exposures. Epidemiology 1996;7:55-61.

38 Gallagher RP, Elwood JM, Rootman J, et al. Risk factors for ocular melanoma: west Canada melanoma study. $\mathcal{F}$ Natl Cancer Inst 1985;74:775-8. 